\title{
UNA CUBIERTA HINCHABLE EN LA ESCUELA TECNICA SUPERIOR DE ARQUITECTURA DE VALLADOLID, ESPAÑA*
}

\author{
(PNEUMATIC DOME IN THE SCHOOL OF ARCHITECTURE AT THE UNIVERSITY OF \\ VALLADOLID/SPAIN)
}

Juan Monjo Carrió, Dr. Arquitecto

Catedrático de Construcción.

Comisión de alumnos de 6.0 curso (Viaje Fin de Carrera)

Escuela Técnica Supeior de Arquitectura

Universidad de Valladolid

$886-41$

\section{RESUMEN}

El artículo contiene una descripción del proceso del diseño y montaje de una cubierta soportada por aire, instalada por los alumnos de 6.0 curso de la Escuela T. S. de Arquitectura de la Universidad de Valladolid, con el objeto de obtener un espacio cubierto de suficiente amplitud para celebrar en él una exposición de materiales y elementos de construcción.

Se realiza una breve descripción del cálculo, asi como de las fases de despiece, cosido de juntas, confección general de la cubierta, replanteo, montaje, anclaje y erección (hinchado) y mantenimiento mediante el uso de ventiladores centrifugos.

El texto se complementa con una amplia colección de dibujos y fotografias relativos a todo el proceso.
SUMMARY

The article contents a description of the design and erection process of a pneumatic dome, set up by the last year students of the School of Architecture at the University of Valladolid in order to obtain a covered space, wide enough to celebrate an exibition of construction materials.

A breve description is made of the calculations as well as the fases of patterns definition, joining, site works, reinforcements, erection and maintenance through ventilators.

The text is completed by a collection of deawings and pictures of the whole process.

\section{INTRODUCCION}

Los alumnos de $6.0^{\circ}$ curso de la Escuela T.S. de Arquitectura de Valladolid viene organizando anualmente un SIMPOSIO sobre CONSTRUCCION Y DISEÑO, como un apoyo más para su viaje Fin de Carrera, en el que tienen lugar tradicionalmente dos tipos de actividades: Por un lado, una exposición de materiales y sistemas constructivos locales y nacionales y, por otra, una serie de charlas y conferencias sobre el tema, dictadas por profesores y especialistas en cada una de las materias que se tocan.

La exposición de materiales y sistemas constructivos se tenia que llevar a cabo en el interior del edificio de la Escuela, en vestibulos y pasillos, con el consiguiente problema de funcionamiento que ello lleva consigo, dadas las no excesivas dimensiones del recinto.

(*) Existe un "video" de 30 minutos de duracion que recoge los diferentes aspectos de este trabajo y que puede ser adquirido en sistema "VHS" O "BETA".

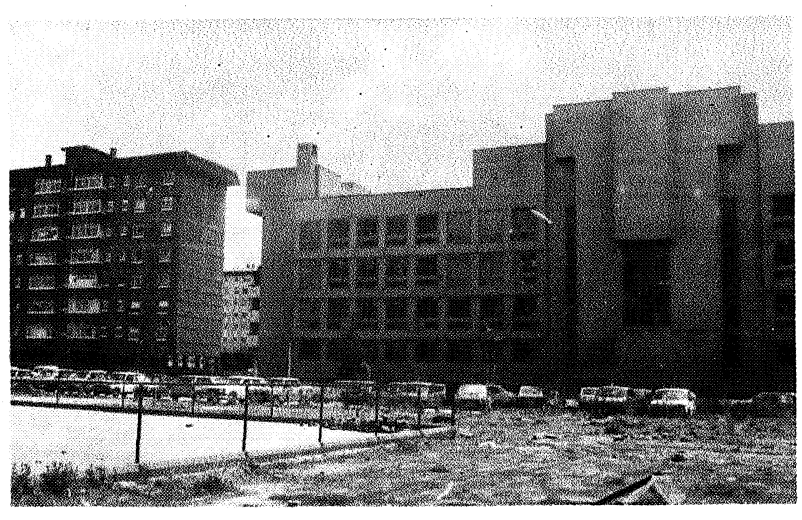

Fig. 1.-Vista posterior de la E.T.S.A.V.

Por ello, ha sido aspiración común de las últimas promociones la utilización de espacios exteriores del edificio que facilitan, por un lado, el funcionamiento independiente de la exposición y permiten, por otro, un acceso más fácil y directo por parte de expositores y visitantes, con mayor disponibilidad de espacio (Fig. 1). 


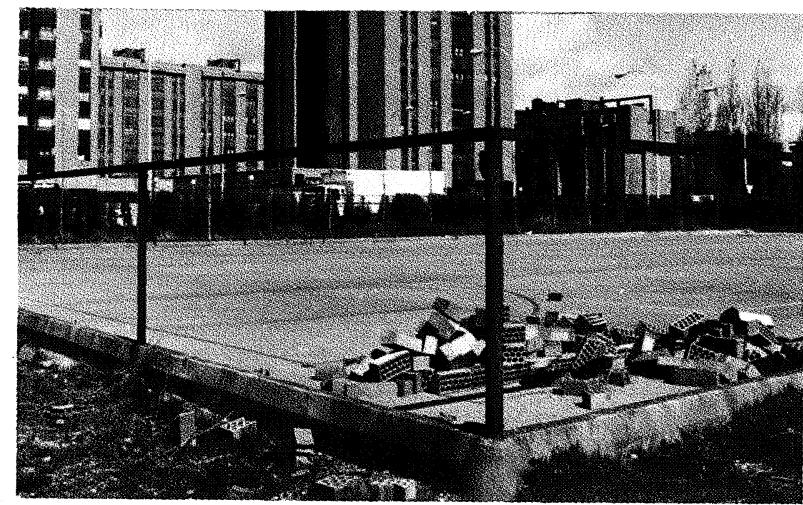

Fig. 2.-Pista polideportiva.

Una de las posibilidades que otras veces se habia planteado era la de utilizar una cubierta hinchable industrial que se colocara en estos espacios exteriores para la celebración de la exposición, pero las dificultades de todo tipo que planteaba su alquiler, no sólo económicas, sino también funcionales y estéticas, hacian inviable la solución. Finalmente, por sugerencia, y con el apoyo técnico del Departamento de Construcción de la Escuela, los alumnos del presente curso (1985-86) han tomado la decisión de construir ellos mismos su propia cubierta hinchable utilizando materiales económicos, de fácil adquisición y manejabilidad, y aprovechando la pista polideportiva del recinto por las ventajas que comporta la existencia de un pavimento y de una barandilla perimetral de anclaje (Fig. 2).

\section{PLANTEAMIENTO}

Partimos, pues, de una superficie rectangular de $40 \times 20\left(800 \mathrm{~m}^{2}\right)$ ya pavimentada y con una barandilla metálica perimetral de $1,20 \mathrm{~m}$ de altura.

Al colocar sobre ella una membrana elástica y someterla a presión interior tenderá a adquirir, en sección, una forma semicircular (Fig. 3) que alcanzará la tensión tangencial propia de las burbujas de jabón, que trasmitirá a su borde donde podemos utilizar la barandilla existente como punto de anclaje.

Como quiera que la barandilla es diáfana, para evitar fugas de aire y poder mantener la presión interior, debemos colocar un faldón desde el anclaje hasta el suelo.

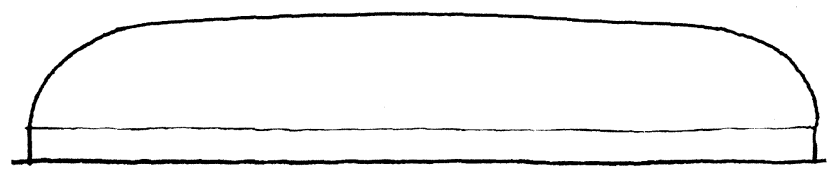

SECCIONN LONGITUDINAL

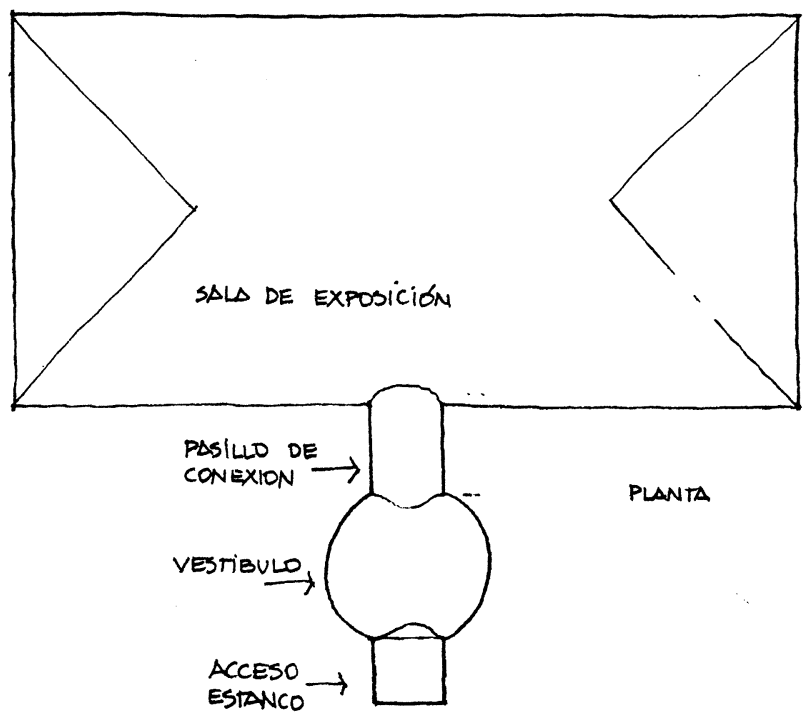

Fig. 4.-Esquema funcional de la cubierta.

Para poder disponer del espacio interior adecuado deberemos conseguir una altura interior de unos $7 \mathrm{~m}$ en el centro, lo que nos permitirá alcanzar altura suficiente incluso en los bordes.

El acceso deberá ser de tal manera que no permita fugas excesivas de aire. Para ello, será conveniente un vestibulo previo que, al mismo tiempo se podrá utilizar como espacio de información y control. Este vestibulo podrá tener planta circular y estar conectado con el rectágulo de la pista central por medio de un pasillo. A su vez, el acceso al vestibulo se podrá resolver por medio de una esclusa de planta cuadrada con dos puertas dobles (Fig. 4).

Al someterse a presión interior, la planta rectangular adquirirá la forma de un semicilindro (o sector de cilindro) al actuar la sección circular como generatriz y el lado mayor como directriz. Los extremos se podrán resolver fácilmente con otros segmentos de cilindro (cuartos de cilindro) de directriz perpendicular a la del principal, simulando bóvedas de rincón de claustro con aristas a $45^{\circ}$ en planta.
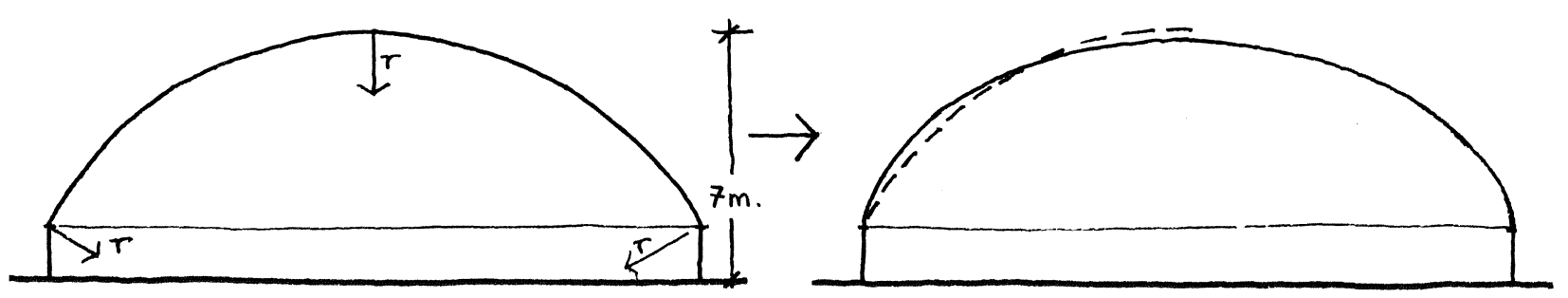

Fig. 3. - Seccion transversal de la cubierta una vez hinchada. 


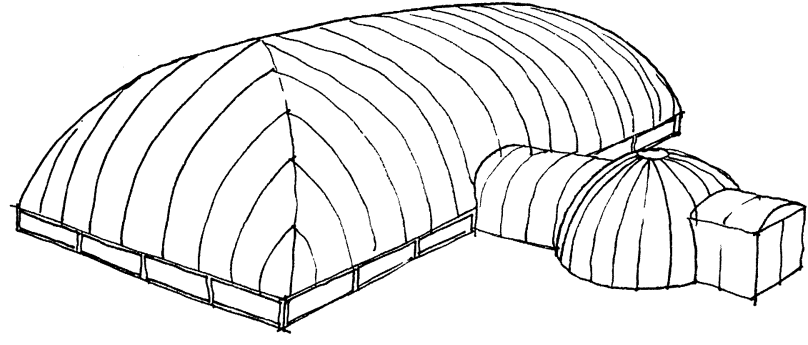

Fig. 5.-Perspectiva de la solución.

El vestibulo, al ser de planta circular, tenderá a la forma semiesférica. El pasillo de conexión podrá ser de nuevo semicilindrico y la esclusa de entrada necesitará una estructura rigida para la colocación de las puertas, por lo que podemos buscar una forma cúbica.

En su conjunto se proyectó, desde un principio, una cubierta como la que aparece en el croquis de la Fig. 5.

\section{CALCULO}

Para asegurar la estabilidad de la cubierta teniamos que resolver dos aspectos fundamentales:

- Por un lado, una membrana suficientemente resistente a la tensión tangencial que en ella se produce.

- Por otro lado, un anclaje que sea capaz de absorber las tracciones que sobre él se acumulan transmitidas por la membrana.

Para cubrir el primer aspecto, debiamos conocer cuál era esa tensión tangencial. Depende de dos acciones: la presión interior, que mantiene la membrana elevada y que, al modo de las burbujas de jabón, introduce una tensión que es función de la propia presión y del radio de curvatura de la membrana según la expresión $\sigma=\frac{\mathrm{Pi} \cdot \mathrm{r}}{2}$ $\left({ }^{*}\right)$ (Fig. 6), y el viento exterior, que puede ser

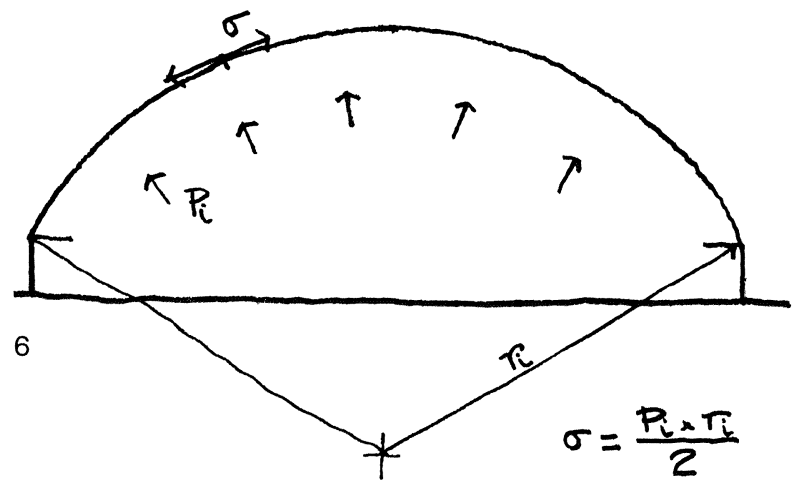

Fig. 6.-Presión interior y Fig. 7.-Acción del viento. positivo o negativo según la inclinación de la superficie de la membrana y que, por tanto, puede suponer una disminución de la acción de la sobrepresión interior o un aumento de la misma, con las consiguientes disminuciones o incrementos de la tensión tangencial sobre la membrana (Fig. 7).

En nuestro caso, el radio de curvatura máximo elegido es de $11,5 \mathrm{~m}$. La presión interior máxima debe ser, según la normativa alemana, para alturas superiores a $8 \mathrm{~m}$ de $30 \mathrm{~kg} / \mathrm{m}^{2}$; ello nos da una tensión tangencial máxima de $172,5 \mathrm{~kg} / \mathrm{m}$. $\mathrm{Si}$, por otra parte, consideramos una succión máxima producida por el viento de $45 \mathrm{~kg} / \mathrm{m}^{2}$, resultará una tensión tangencial alternativa de $258,7 \mathrm{~kg} / \mathrm{m}$, que por ser superior a la anterior, la tomamos como tensión máxima de cálculo. Si aplicamos un coeficiente de seguridad de 2, por el tipo y proceso de construcción, resultará una tensión de $514,4 \mathrm{~kg} / \mathrm{m}$, expresable también como $26 \mathrm{~kg} / 5 \mathrm{~cm}$.

En cuanto al anclaje, el uso de la barandilla existente nos garantiza su resistencia.

Por otra parte, aunque para la presión interior necesaria hemos aceptado, según la normativa alemana, una de $30 \mathrm{~kg} / \mathrm{m}$ que nos asegura la estabilidad estructural, debemos tener en cuenta también las necesidades funcionales. Para ello consideramos un número de renovaciones de aire de 1,5 cada hora, lo que nos da una necesidad de $2 \mathrm{kw}$ de potencia en los aparatos de impulsión que, para mayor seguridad y en evitación de problemas por la rotura de los mismos, estableceremos en $6 \mathrm{kw}$ ( 3 ventiladores de $2 \mathrm{kw} / \mathrm{Ud}$ ).

\section{EJECUCION}

\subsection{Confección}

Una vez obtenidos estos datos por cálculo teórico veamos cómo se resolvió la cubierta constructivamente.

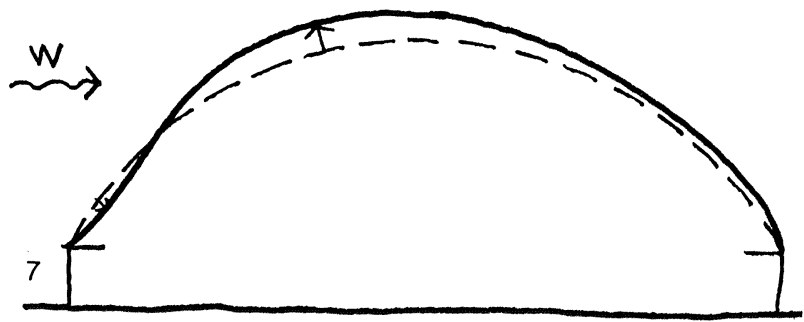

(*) En puridad, esta fórmula es adecuada para superficies esfericas donde los dos radios de curvatura en cualquier punto son iguales. En los casos de superficies cilindricas, al ser uno de los radios de giro $\infty$, la fórmula correcta sería $\sigma=P i$. $r$. Sin embargo, en nuestro caso, al estar los bordes rematados con otras superficies cilindricas y ser un rectángulo no excesivamente alargado, la membrana tiende a adoptar una superficie parecida al elipsoide, por lo que, por aproximación, parece más adecuado el uso de aquella fórmula. 


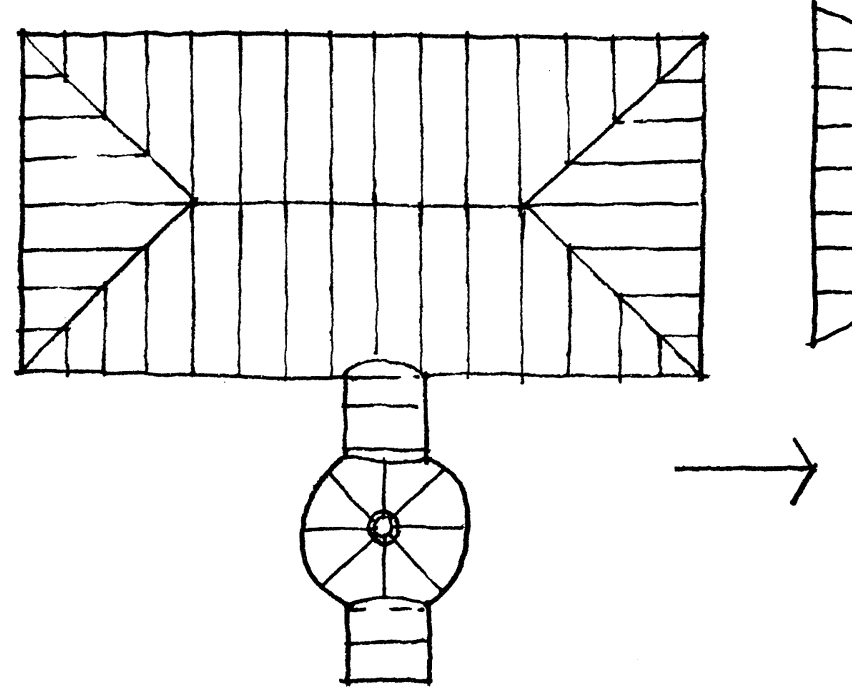

Fig. 8. - Esquema de despiece.
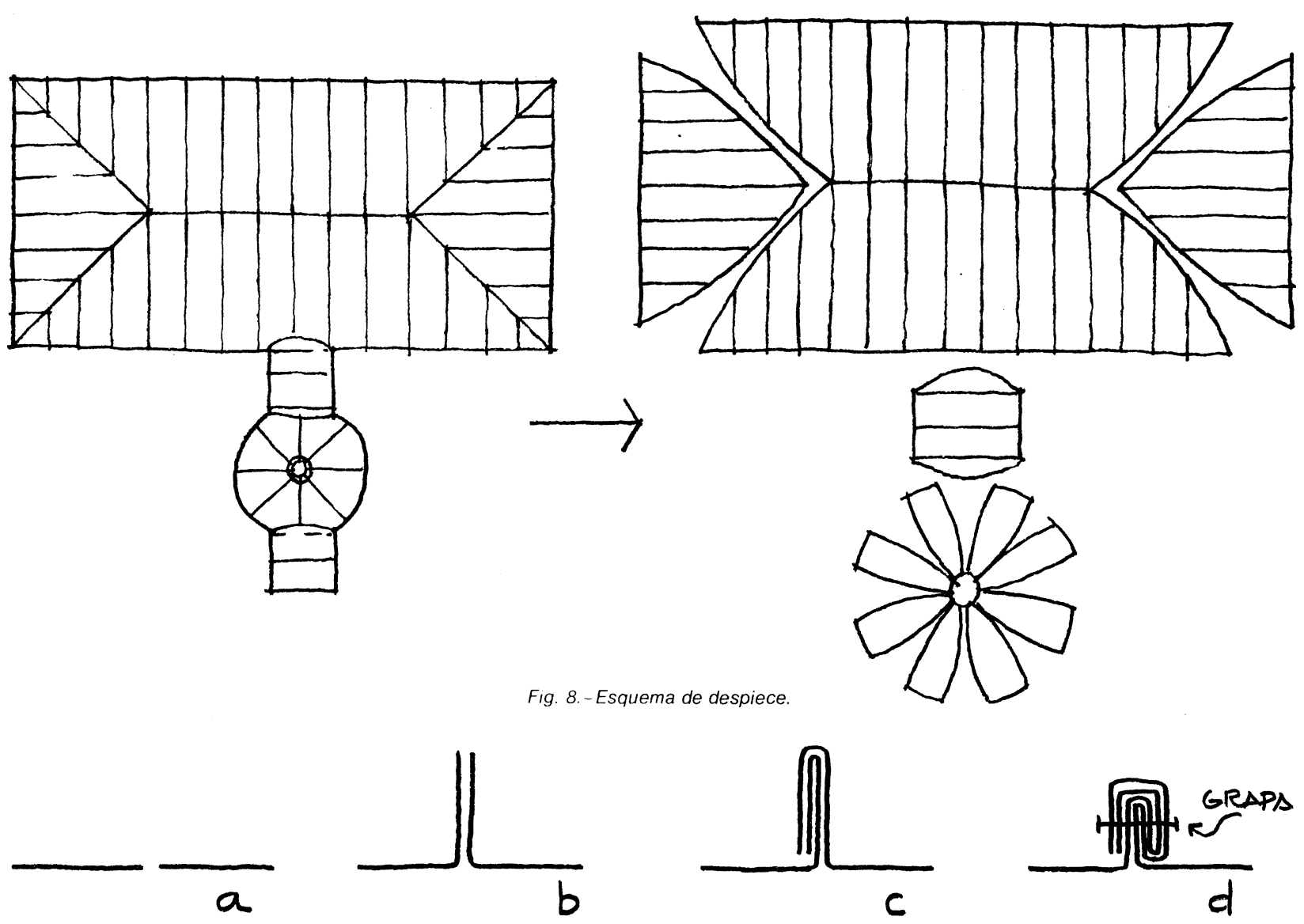

Fig. 9.-Unión por doble plegado.

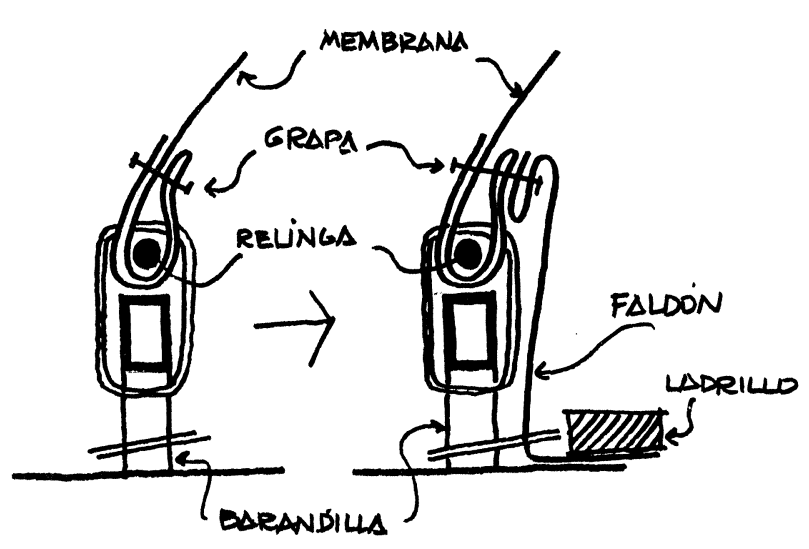

Fig. 10 a.-Anclaje a barandilla y faldón.

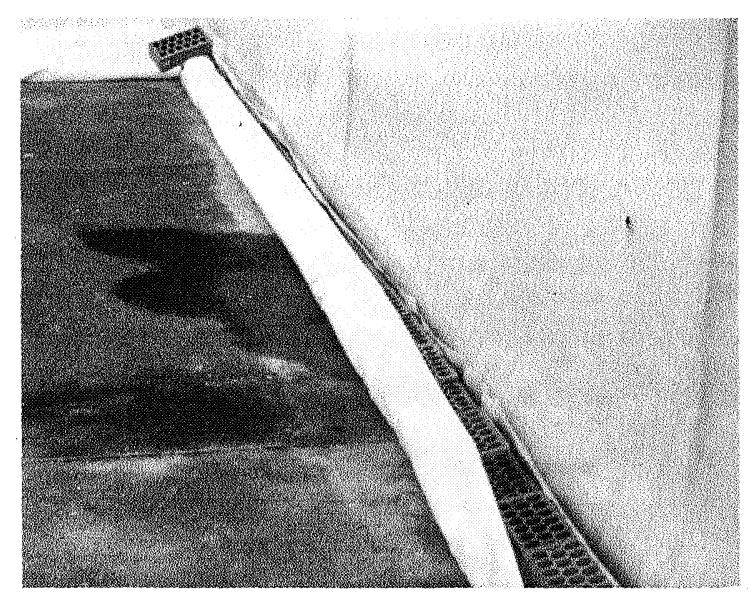

Fig. 10 b.-Faldon interior.
En primer lugar, el despiece de la membrana para una fácil confección. Para una superficie cilindrica la descomposición más lógica es la de las franjas rectangulares paralelas según los circulos máximos. Los extremos, al ser una planta rectangular, se resolvieron con cuartos de cilindros según la dirección perpendicular. Los anchos de las franjas se debieron adaptar a los que ofrecia el mercado. En cuanto al vestibulo semiesférico, se utilizaron franjas triangulares mixtilineas según los meridianos de la esfera, en forma de gallones (Fig. 8).
Las uniones entre las distintas franjas tenian que ser resistentes a la tracción e impermeables. Para ello se utilizó un doble plegado con cosido por grapas metálicas separadas $5 \mathrm{~cm}$ entre si (Fig. 9).

El anclaje de la cubierta principal se hizo a la barandilla existente por medio de una relinga rígida de redondo metálico, introducido en el dobladillo de borde, que se sujetó a dicha barandilla me- 


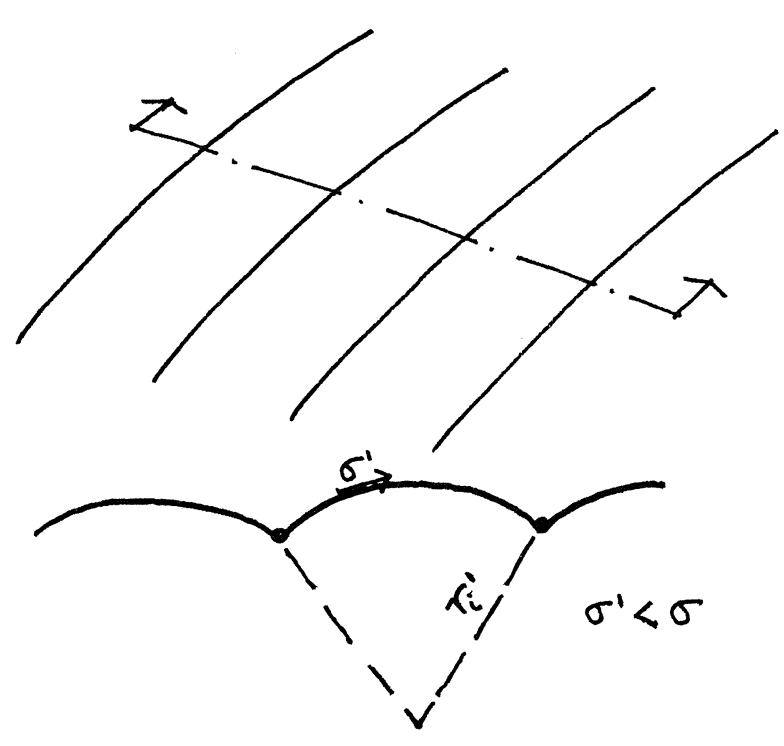

Fig. 11.-Disminución de $\sigma$ por disminución de $\tau_{i}$.

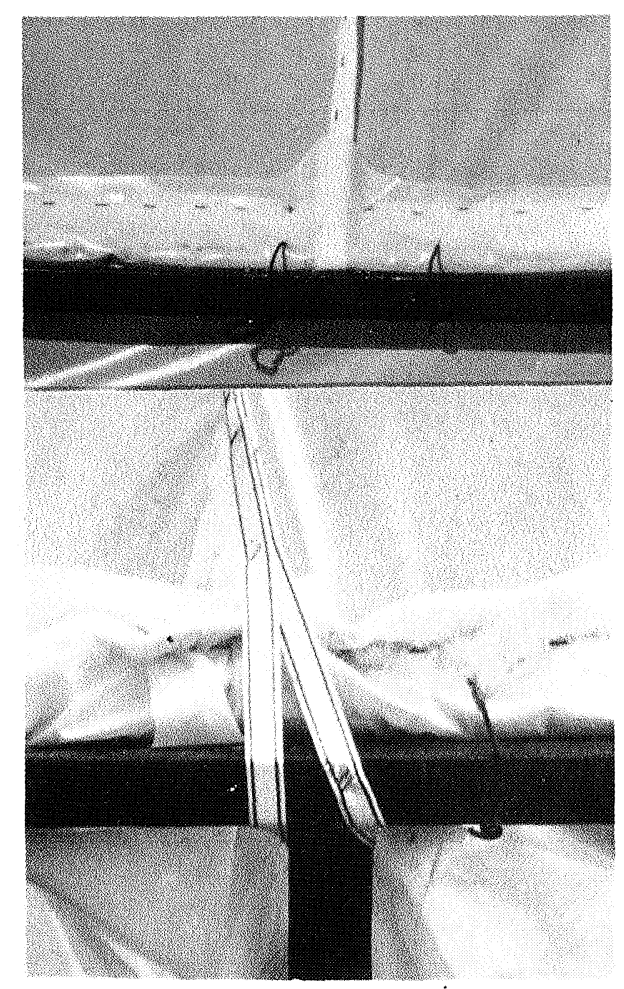

Fig. 12.-Anclaje.

diante unos ganchos. Al mismo tiempo, y para evitar fugas de aire, se cosió un faldón por el interior que se sujetó a la membrana antes de la relinga y se colgó hasta afirmarse en el suelo por medio de peso permanente (ladrillos sueltos) (Figs. 10a y 10b).

Consideramos también la posibilidad de colocar cables transversales a la cubierta principal los cuales, anclados a la barandilla, sujetarian el conjunto de la membrana dividiéndola en franjas

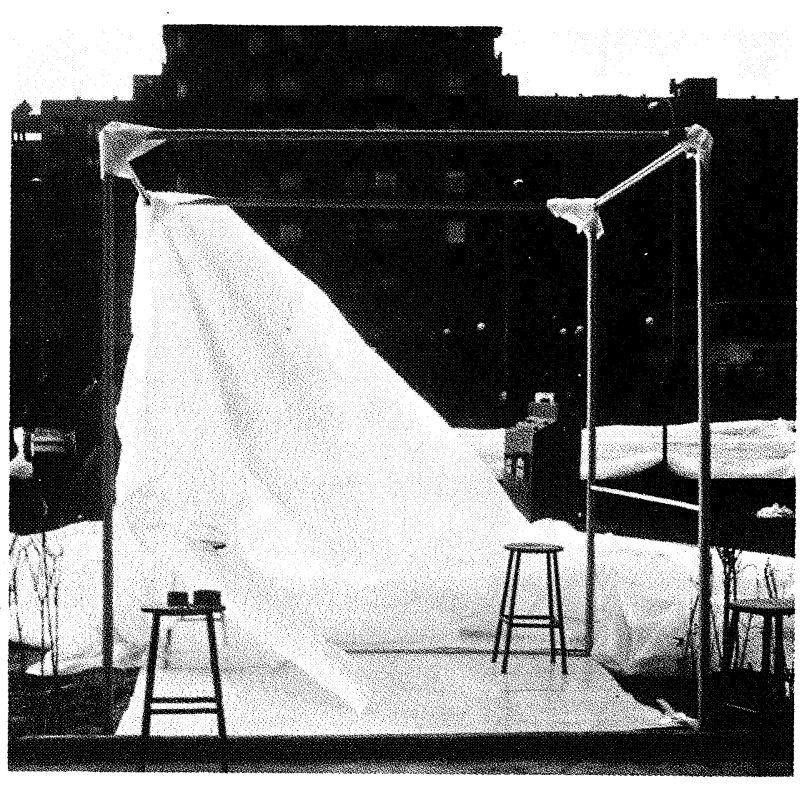

Fig. 13.-Estructura de entrada.

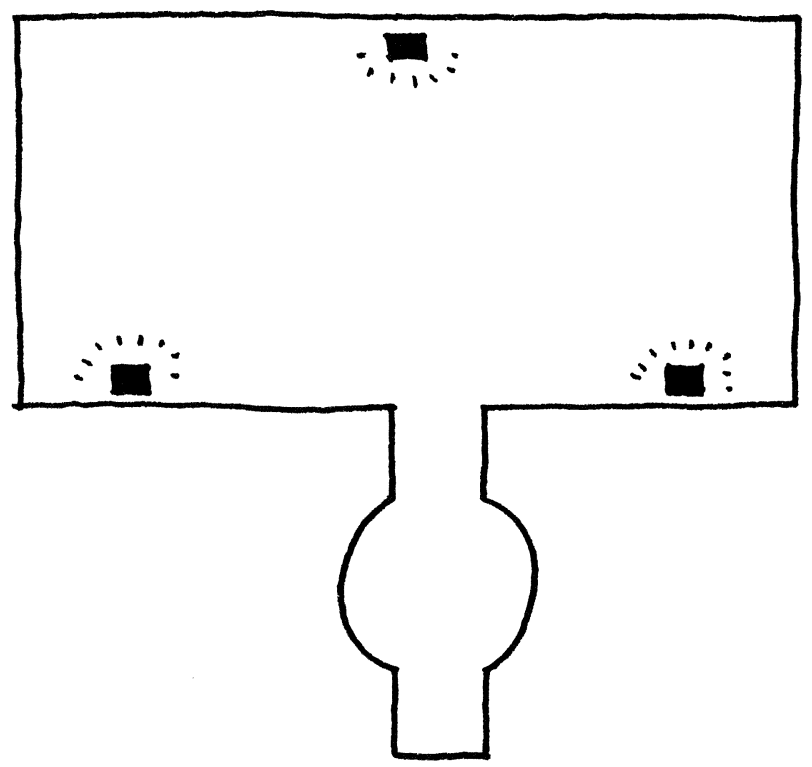

Fig. 14. - Situacion de ventiladores de impulsion

que, en caso de aumentar la presión interior o la succión al viento, se abombarian disminuyendo el radio de curvatura y, por tanto, la tensión tangencial (Fig. 11). Sin embargo, durante la confección se comprobó que las uniones de las láminas, al tener triple pliegue, resultaban muy reforzadas y actuaban como líneas más rigidas y, por tanto, como cables transversales, por lo que se optó por sujetar en los extremos de esas uniones trozos de "cinta de persiana" como refuerzo, que se ancló posteriormente a la barandi- 
Ila y cumplió perfectamente su misión, sobre todo en las aristas de los extremos y las intersecciones entre tramos diferentes (Fig. 12).

El acceso es un punto dificil de la cubierta, ya que puede suponer una salida importante de aire con la consiguiente disminución de la presión interior. Por ello, se hacia necesaria, como queda dicho, una esclusa con doble puerta. Para conseguirlo se estableció una estructura metálica antes del vestíbulo semiesférico que permitió colocar dos puertas dobles para el acceso a todo el conjunto. Esta estructura se cubrió también con la misma membrana (Fig. 13).

La impulsión del aire, que permitía alcanzar la presión interior que soporta la membrana, se realizó con 3 ventiladores centrifugos colocados lo más repartidos posible para obtener una impulsión uniforme en todo el recinto (Fig. 14).

Cada ventilador tenia una toma de aire exterior directa (Fig. 15).

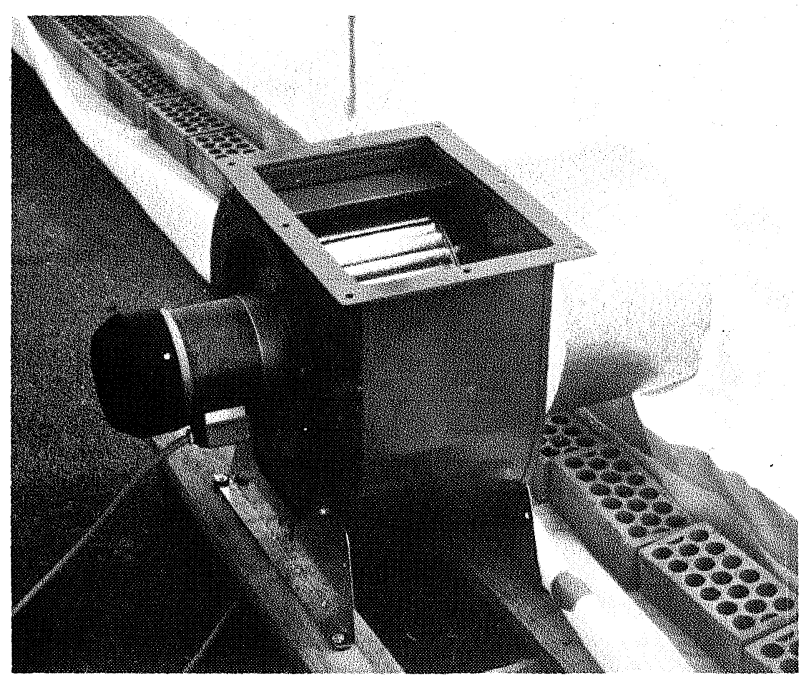

Fig. 15.-Ventilador centrifugo

\subsection{Materiales}

Resuelto el diseño constructivo, veamos los materiales e instrumentos.

La cubierta se confeccionó mediante lámina de polietileno, de $2 \mathrm{~m}$ de ancho. Este es un material económico, muy flexible y fácilmente trabajable, lo que lo convierte en el adecuado para una solución temporal como ésta.

El espesor más conveniente de los que ofrece el mercado es el de 800 galgas que equivale a dos décimas de milimetro. Su resistencia, en el caso más desfavorable es de $300 \mathrm{~kg} / \mathrm{cm}^{2}$, que equivale a $30 \mathrm{~kg} / 5 \mathrm{~cm}$ que es superior a lo que se ha determinado en el cálculo previo y, por tanto, suficiente para este objetivo (Fig. 16).

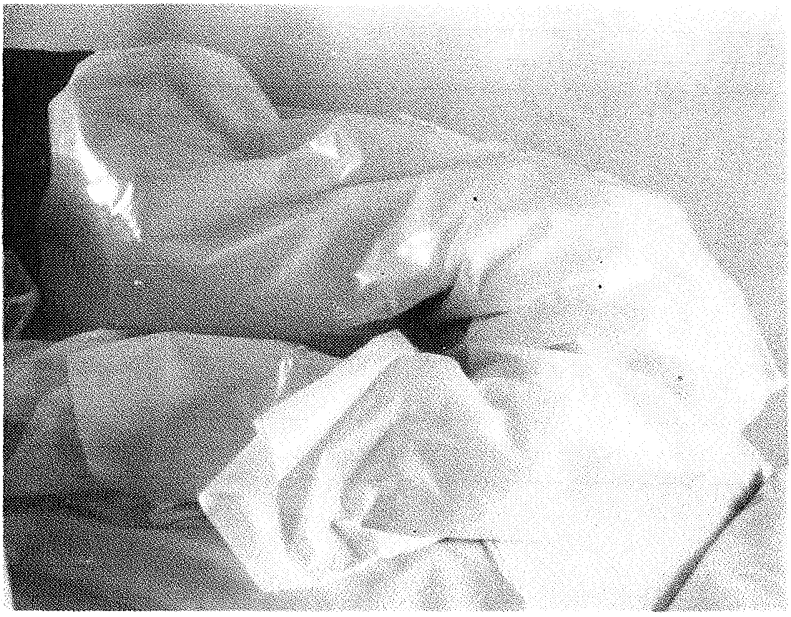

Fig. 16.-Polietileno de 800 galgas.

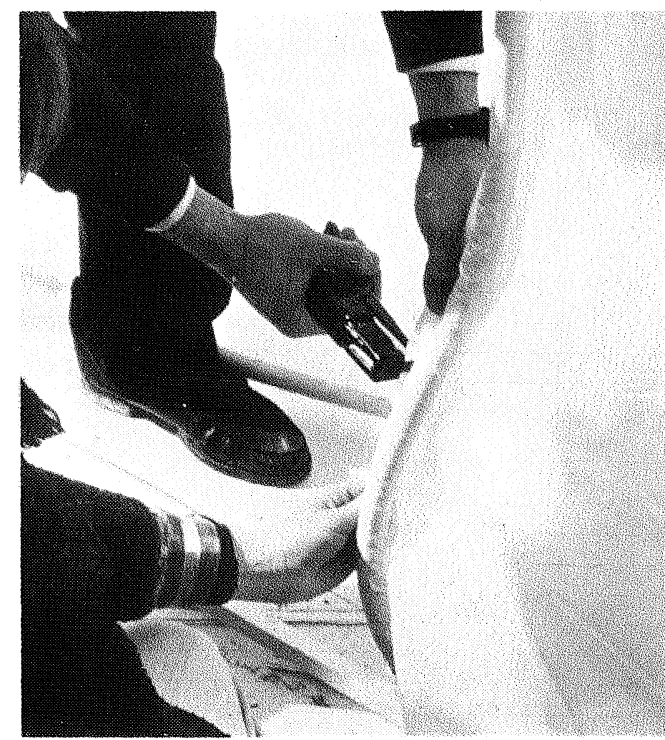

Fig. 17.-Grapado.

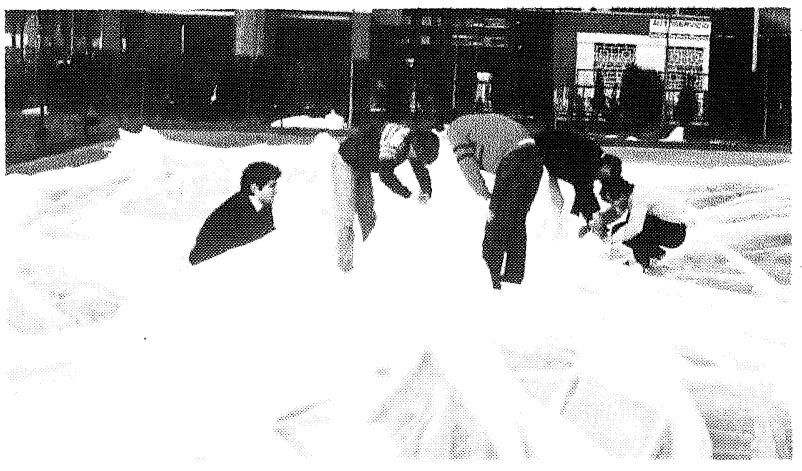

Fig. 18. - Cosido de partes "a pie de obra" 


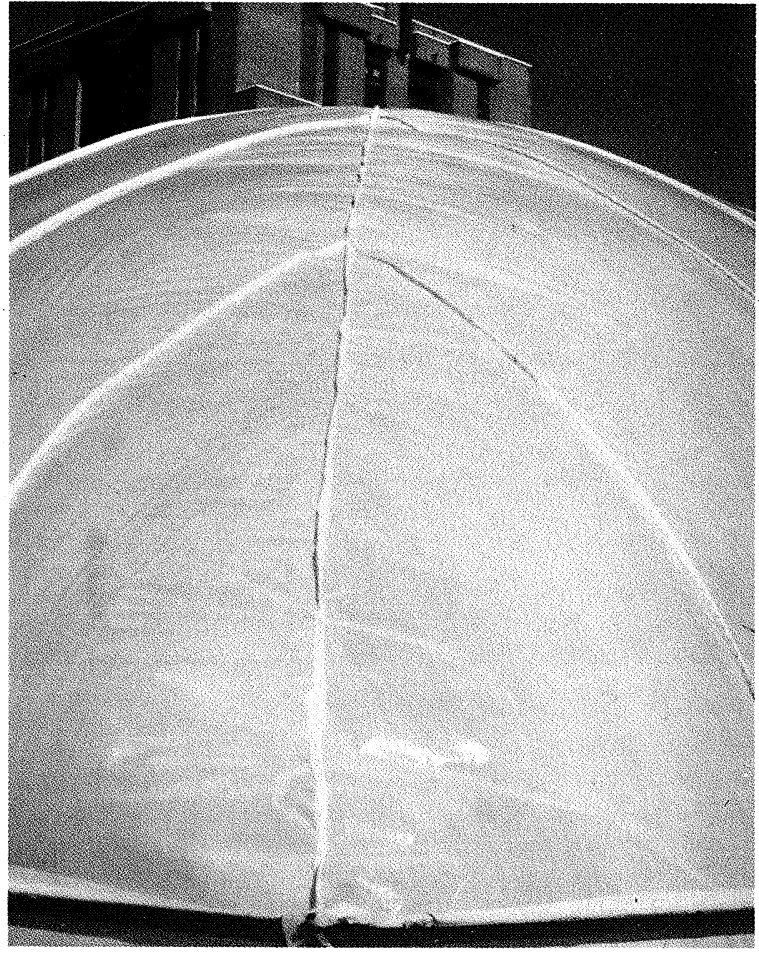

Fig. 19.-Arista convexa.

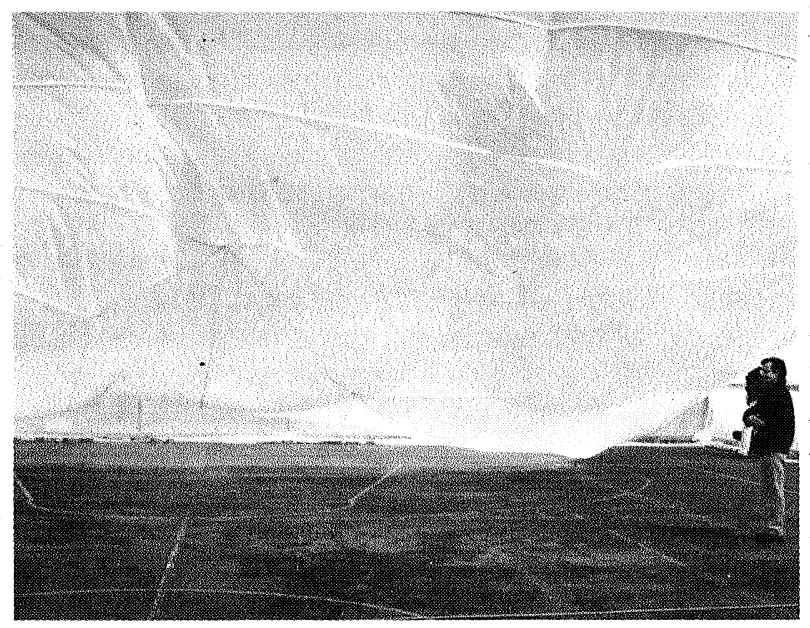

Fig. 20 a.-Hinchado. Vista interior.
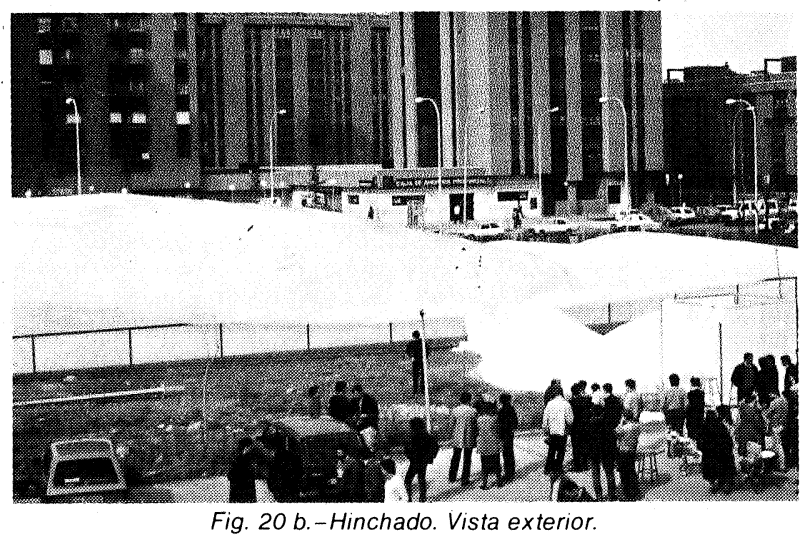

(C) Consejo Superior de Investigaciones Científicas Licencia Creative Commons 3.0 España (by-nc)
El cosido de las diferentes láminas se realizó mediante grapas industriales de acero protegido contra la corrosión (Fig. 17).

La impulsión de aire se consiguió por medio de ventiladores centrifugos de $2 \mathrm{kw}$ de potencia cada uno.

Para la confección, se debian cortar las franjas al tamaño adecuado para, una vez unidas, conseguir las formas cilindrica y esférica diseñadas. Para ello se procedió a un replanteo previo, trazando sobre el suelo el despiece de las franjas de la superficie desenrollada, y se cortó el plástico con sus medidas exactas (Fig. 18).

Una vez cortadas cada una de las franjas de polietileno se procedió a su cosido procurando mantener la linealidad de las uniones y la uniformidad del mismo para evitar futuras arrugas. Se unieron las franjas correspondientes a cada uno de los segmentos de cilindro: por un lado el principal, por otro los de los extremos y, por fin, el del pasillo de conexión, para terminar con la semiesfera.

Como complemento estructural se introdujo un refuerzo lineal en los puntos donde se acumulan las tensiones mediante "cinta de persiana", antes mencionada (Fig. 19).

Una vez confeccionados estos segmentos independientes, se unieron entre si por el mismo procedimiento. En primer lugar la cubierta principal. A continuación se colocó la relinga y se enganchó a la barandilla, sujetando el faldón ya cosido. Después, el vestíbulo semiesférico.

Una vez terminadas estas uniones, se pusieron en marcha los tres ventiladores para proceder al hinchamiento y consiguiente izado de la cubierta, que se llevó a cabo en unos 20 minutos (la membrana estaba mojada como consecuencia de la lluvia caida el dia anterior; de lo contrario el tiempo de hinchado hubiera sido menor). (Fig. 20).

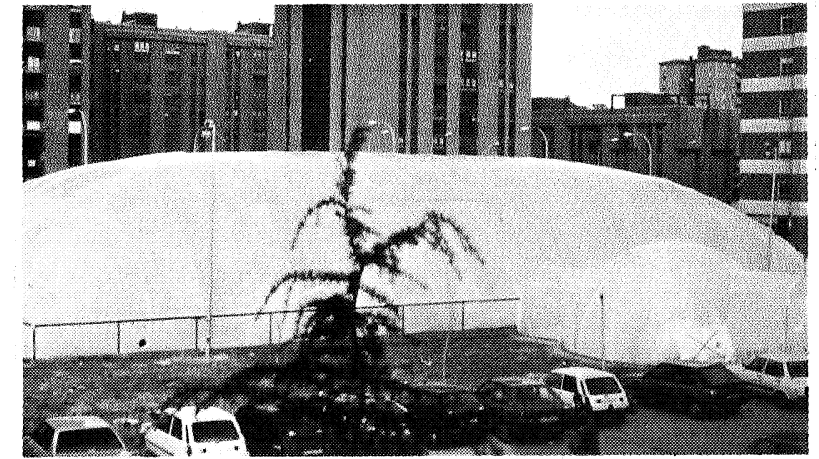

Fig. 21 a.-Vista general. 


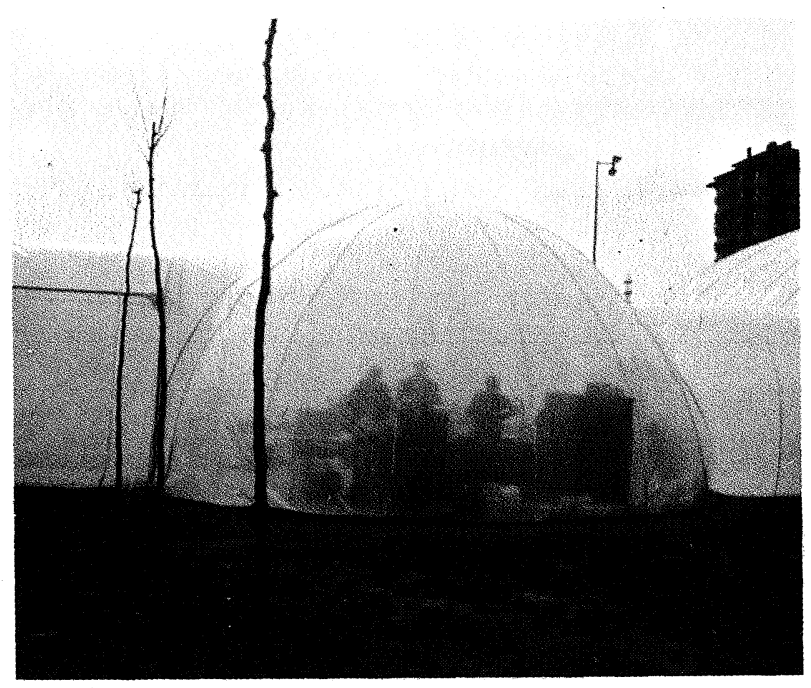

Fig. 21 b.-Vestibulo semiesférico.

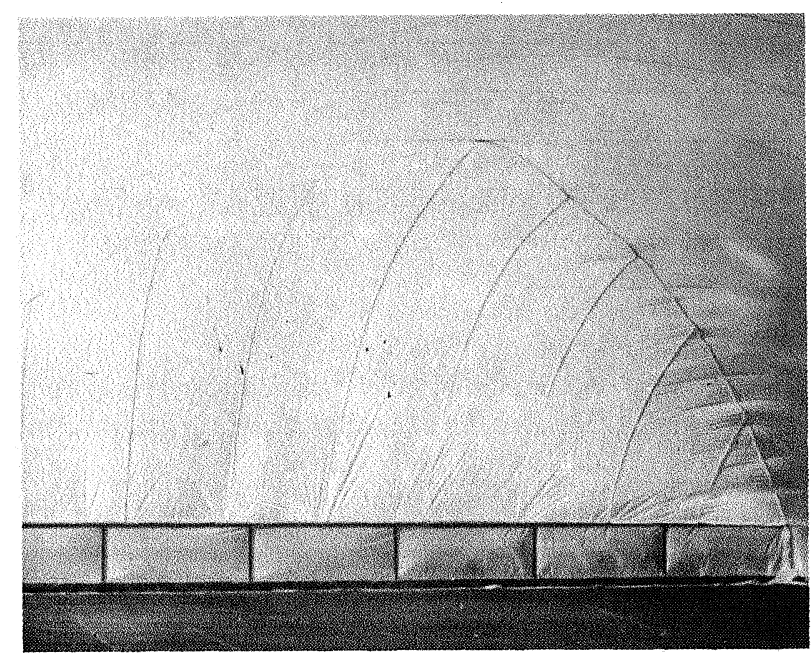

Fig. 21 d.-Comision de alumnos Final de Curso.

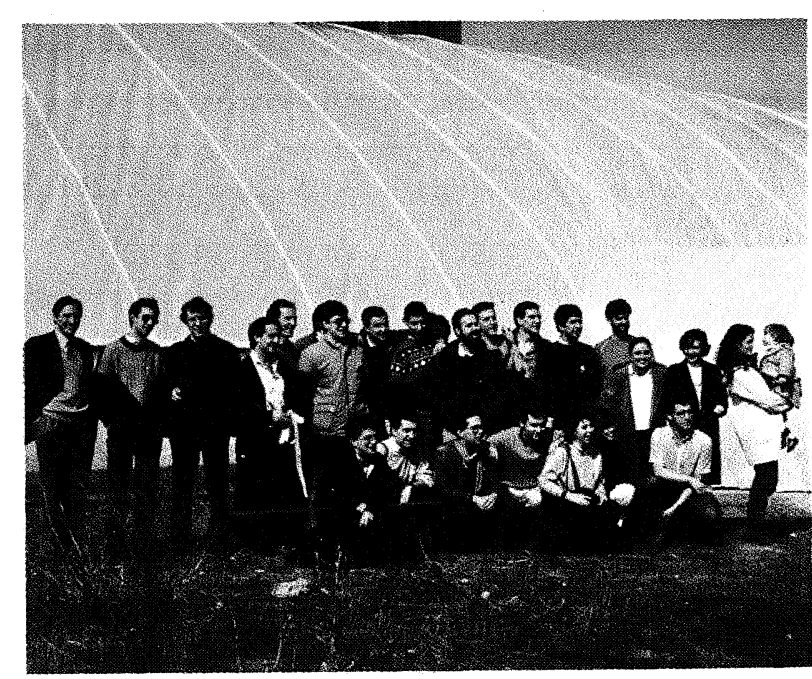

Fig. 21 c.-Vista interior.

Una vez levantada la membrana, se deja en marcha un solo ventilador, que resulta más que suficiente para mantenerla elevada.

La cubierta ya puede utilizarse. El acceso de los materiales a exponer se realiza por la doble puerta del vestibulo semiesférico. El interior resulta totalmente diáfano y suficientemente luminoso, adecuado, pues, para los fines previstos.

El resultado final es funcionalmente correcto y estéticamente aceptable (Fig. 21).

Toda la operación de confección y elevación ha supuesto el trabajo de alumnos durante dias y la cubierta se mantuvo en perfectas condiciones durante la semana que duró la exposición. 